\title{
A INCONFIDÊNCIA MINEIRA: LITERATURA E HISTÓRIA EM DOIS TEMPOS
}

Flavio Felicio Botton

Professor de Literatura - UniABC
RESUMO: Este artigo tem por objetivo propor uma possível função para a literatura histórica, por meio da análise da peça de Castro Alves, Gonzaga ou a Revolução de Minas.

PALAVRAS-CHAVE: Literatura; História; Literatura Histórica; Castro Alves;

Dramaturgia

THE INCONFIDÊNCIA MINEIRA:

LITERATURE AND HISTORY IN TWO PERIODS

ABSTRACT: This paper aims at proposing a possible function for the historical literature, by analyzing the Castro Alves' play Gonzaga ou a Revolução de Minas.

KEYWORDS: Literature; History; Historical Literature; Castro Alves; Playwrite 
Uma diferenciação como a célebre, e incansavelmente repetida, feita por Aristóteles entre literatura e história nunca foi tão necessária quanto na modernidade, que se entretêm em quebrar todos os paradigmas possíveis. Dizia o filósofo que a história conta o que aconteceu, enquanto literatura conta o que poderia ter acontecido. As dificuldades começariam com a própria literatura grega, que combinava indiscriminadamente mito e história, e seguiriam por todo o trabalho de todos os historiadores e teóricos da literatura.

Se pensarmos a história como uma tentativa de reconstruir um passado, trilharemos algumas etapas, não necessariamente nessa ordem, tais como escolha de uma época e/ou de uma personalidade, recolha de documentos e, havendo possibilidade, de depoimentos sobre o tema. É claro que, por mais material que se ponha a disposição de um historiador, uma parte do "real" ficou retida inexoravelmente no passado e não poderá, de maneira alguma, ser resgatada. Esses entremeios, que se esquivam ao registro, precisam, ainda assim, de um processo de reconstrução para dar um sentimento de totalidade à história. Nesse momento, é preciso preencher os vazios judiciosamente, procurando como seria a forma mais provável de eles terem realmente acontecido. Sem perceber, entrou-se no terreno do que "poderia ter acontecido", no terreno da literatura. Obviamente, não se quer dizer com isso que a história seja outra forma de literatura, mas há que se ressaltar que as fronteiras não são tão claras quanto pareciam ao filósofo.

Da mesma maneira, mais e mais historiadores têm procurado a literatura como forma privilegiada de acesso ao imaginário de uma sociedade, confundindo os perímetros divisores também pelo outro lado (JATAHY, 2006).

Assim, se nos conceitos aparentemente absolutos de literatura e história não estamos em terreno seguro, as fronteiras desenhadas não poderiam ser mais frágeis ao tratarmos de algo que se move em campo aparentemente híbrido, como a literatura ou a arte histórica, entendidas aqui como peças de ficção que têm, como ponto de partida para o desenvolvimento de seu enredo, um episódio da história.

O que esse trabalho pretende é discutir uma possível função da arte histórica por meio da análise de um acontecimento que é, anos depois, reelaborado por uma obra literária. Procuraremos então cotejar o conhecimento histórico que se tem a respeito do mais famoso e importante movimento da história colonial brasileira, a Inconfidência Mineira, com uma obra ficcional que a toma como epicentro. Será analisada a peça de 
Castro Alves, Gonzaga ou a Revolução de Minas produto único da dramaturgia do poeta baiano.

\section{A histórica Inconfidência Mineira}

Os pouco mais de cem anos que antecedem a independência nacional formam uma época plena de conspirações contra a nossa metrópole européia. Apesar de bem contextualizadas com os acontecimentos internacionais, como a Revolução Francesa e a Independência dos Estados Unidos da América, as rebeliões desenroladas no território brasileiro mostram os desejos e a realidade do local em que cada uma delas brotou. Como percebe FAUSTO (2002), afirmam-se os rebeldes como "mineiros", "baianos", "pernambucanos" e nunca simplesmente como brasileiros.

Dentre as tantas ocorridas, como a Guerra dos Mascates, de 1710 e a Revolução de 1817, ambas em Pernambuco, ou a Conjuração dos Alfaiates, de 1798, deflagrada na Bahia, a que até os nossos dias mais reverbera é a Inconfidência Mineira.

Dela foram extraídos, mesmo que a posteriori, um ideal de nação livre, bem como o mártir de uma nobre causa. Esse fato é ainda mais intrigante quando vemos que a conjuração não chegou, em ponto algum, a se concretizar, mantendo-se apenas e tão somente como boas intenções.

Porém, é de interesse perguntar, quais teriam sido suas propostas e em que universo o movimento teve lugar.

Como se sabe, as primeiras notícias sobre a descoberta do ouro na região das Minas datam do final do século XVII. Levadas com rapidez, espalham-se pelo Brasil e, céleres, chegam a Portugal. Entre os anos de 1705 e 1750, os livros de navegação registram a saída de dez mil pessoas da metrópole em direção à colônia, grande parte delas com o sonho do ouro mineiro na algibeira (FAUSTO, 2002).

Com o passar do tempo, a administração portuguesa começa a se impor em território que, até então, não lhe interessava e os pequenos povoados tornam-se vilas que ganham autonomia em relação à capitania de São Paulo: nasce, em 1720, a capitania de Minas Gerais. 
A sociedade que se forma na nova capitania é sensivelmente diferente de suas irmãs nordestinas. Essas últimas, baseadas na monocultura canavieira e no trabalho escravo, constituem um universo fechado e auto-suficiente. Já nas Minas, uma propriedade abrigava grande diversidade de atividades, conforme apontam GANCHO e TOLEDO (1991), tais como a lavra, a pequena agricultura de subsistência, a criação de animais, entre outras ainda. Além disso, essas propriedades eram dependentes do abastecimento e do escoamento de produtos por meio do comércio com o restante da província. Configura-se, desde aí, uma sociedade mais aberta e de maior flexibilidade, em que vale a pena destacar a presença de trabalhadores livres que podiam ser negros, mulatos ou brancos, assim como a existência de uma camada sem nobreza, mas que, dependendo da sorte com o ouro, poderia vir a comprar os títulos ou tornar-se rico proprietário de terras.

Para o nosso propósito, vale a pena citar a conclusão de GANCHO e TOLEDO sobre as Minas do período: "Numa sociedade assim formada, os preconceitos social e racial importam menos que a riqueza; assim, será possível encontrar mulatos pertencentes à camada mais alta da sociedade, bem como negros escravos que compram sua liberdade e passam a ser trabalhadores livres" (1991, p. 19).

Isso, unido ao desenvolvimento econômico proporcionado pelo ouro e pelos diamantes, forma uma agitada vila com intensa vida urbana e cultural que assistirá ao surgimento de oficiais como Aleijadinho e de poetas como o bacharel Cláudio Manuel da Costa e do ouvidor de Vila Rica, Tomas Antonio Gonzaga.

Na segunda metade do século XVIII, porém, a economia mineira já começa a conhecer uma fase de declínio. A extração do ouro já não se dava no mesmo ritmo dos primeiros anos, o que, entretanto, não é um fato aceite pela coroa portuguesa, que não só pretende manter os níveis de contribuição, como também elevá-los.

Um grande catalisador a unir os integrantes de Inconfidência foi a chegada de um novo governador, Cunha Meneses, que trouxe o seu próprio escalão, em detrimento da elite das Minas. O novo líder, além de lançar ao desprestígio os poderosos locais, afetou também os interesses econômicos dos "homens ricos que exerciam cargos públicos, pois (...) passou a dirigir a especulação e o contrabando de ouro em seu benefício" (GANCHO e TOLEDO, 1991, p. 35). 
A situação se agrava ainda mais com a nomeação do Visconde Barbacena em substituição a Meneses, por fim de mandato. Às ordens para investigar todos os contratos firmados entre a coroa e particulares, soma-se a possibilidade de o Visconde lançar a "derrama", um tributo a mais a ser pago por todos os habitantes da capitania (FAUSTO, 2002).

Em sua maior parte, os prejudicados por essas últimas medidas adotadas pela coroa portuguesa eram membros da elite mineira, classe de origem da maioria dos integrantes da Inconfidência. Eram ricos proprietários, Cláudio Manuel da Costa, advogado que trabalhou em cargos importantes da administração pública, e o desembargador Tomás Antonio Gonzaga. A exceção deve ser feita apenas a Joaquim José da Silva Xavier, o Tiradentes, portador das insígnias mais humildes do quadro de oficiais do exército e que já havia perdido suas propriedades por dívidas. De todos, foi o único a ser executado, em parte, por ter assumido toda a culpa durante o inquérito.

As intenções do movimento são bastante abrangentes e variadas e, da mesma forma, confusas, pois delas temos apenas os registros do processo. A mais subversiva aos olhos da metrópole toma forma na separação em si, mas também seria bastante perturbadora a proposta de proclamação de uma república com capital em São João DelRey, presidida, em seus três primeiros anos, por Tomás Antonio Gonzaga (GANCHO e TOLEDO, 1991).

Um ponto que nos interessa fundamentalmente era bastante controverso entre os membros da Inconfidência: a abolição da escravatura. Como boa parte da força de trabalho na capitania era escrava e muitos dos conspiradores eram proprietários de terras, havia quem defendesse que a abolição traria consigo o colapso econômico. Segundo FAUSTO (2002), houve mesmo uma proposta de medida “intermediária” em que seriam livres os escravos nascidos no Brasil.

Como é amplamente conhecido, o movimento foi delatado por Joaquim Silvério dos Reis, o que levou ao seu prematuro fim. Reis era um dos maiores devedores da coroa portuguesa e obteve, com o ato da delação, o perdão das dívidas todas, além de alguns privilégios econômicos.

Tiradentes, tido como agitador político e maior entusiasta do movimento foi, como dissemos, executado na forca e, ainda, esquartejado e exposto a visão pública. Já os outros tiveram penas bem mais suaves. O crime de lesa-majestade deveria ser punido 
com a morte, mas, depois de um processo bastante falacioso, de dois anos, uma carta régia recomendava a comutação da pena em degredo. Cláudio Manuel da Costa não usufruiu do teor da carta de D. Maria I, pois morreu, não se sabe se por suicídio ou se por assassínio, ainda na prisão. Alguns inconfidentes viveram em África por muitos anos e puderam voltar ao Brasil após a Independência. Tomás Antonio Gonzaga foi para Moçambique, onde se casou e viveu até os 67 anos (OLIVEIRA, 1985).

\section{A Inconfidência sob a pena do Poeta dos Escravos}

Um dos mais conhecidos nomes do Romantismo brasileiro teve breve passagem pela dramaturgia: uma única experimentação em texto teatral. Em 1867, Castro Alves encontrava-se bastante defasado em relação ao seu contexto artístico, quando terminou a composição de seu Gonzaga ou a Revolução de Minas. Anos antes disso, já haviam subido à cena, algumas das mais consistentes peças do teatro realista de José de Alencar: O Demônio Familiar é de 1857, As asas de um anjo, de 1858, e Mãe, de 1860. Além disso, mesmo em palcos franceses, já há muito a fórmula usada pelo poeta achava-se esgotada. Como aponta Décio de Almeida Prado: "O romantismo continuava como fonte poética, porém, no palco, já dera lugar a outros projetos estéticos" (PRADO, 1999, p. 73).

Ainda assim, o autor de $O$ Guarani, vendo no jovem moço, um dramaturgo de futuro, recomenda, em carta, que Machado de Assis conheça o trabalho de Castro Alves, "um discípulo de Victor Hugo, na arquitetura do drama e no colorido da idéia" (ALENCAR apud FARIA, 2001, p. 409). Uma das poucas ressalvas que Alencar faz ao texto poderia ser tomada como elogio ao poeta, ainda que maculasse a obra do dramaturgo iniciante. A reprimenda dizia: "Há no drama Gonzaga exuberância de poesia" (ALENCAR apud FARIA, 2001, p. 410). Machado segue a indicação, conhece e aprova a obra dramática de Castro Alves, afirmando com fé que, no futuro, o jovem “conseguirá separar a língua lírica da dramática” (ASSIS, apud FARIA, 2001, p. 416).

A comparação feita por Alencar foi aproveitada também por Alfredo Bosi, em

sua História Concisa da Literatura Brasileira (2004), o que nos mostra certa consistência do poeta, dado que a influência é sempre a mesma, seja no teatro, seja na 
poesia: "é a voz de Victor Hugo, satirizador de tiranos e profeta de um mundo novo, que se faz ouvir com fascínio crescente” (BOSI, 2004, p. 120).

O que mais interessa a este trabalho, no entanto, é lembrar a descrição do tema mais freqüente na obra do poeta baiano. O mesmo Alfredo Bosi (2004) descreve Castro Alves como um representante de uma situação nova para o país: desenrola-se a crise do cenário rural e o conseqüente consolidar-se, ainda que lento, da cultura urbana e dos ideais democráticos que trazem o despontar de uma aversão pela "moral senhor-eservo" que conspurcava o ambiente da família brasileira. A poesia de Alves será a materialização desse momento, em que começa a incomodar às elites a presença do escravismo. As temáticas do tráfico e das crueldades inerentes ao contexto escravista aparecem então como o cerne da obra do poeta baiano.

A mesma visão sobre a obra de Castro Alves é compartilhada por Antonio Candido. O autor da Formação da Literatura Brasileira nos descreve o arquétipo que se formou em torno da imagem do poeta: "o bardo que fulmina a escravidão e a injustiça, de cabeleira ao vento" (CANDIDO, 1997, p. 241). Da mesma forma que o vulto de Gonçalves Dias está indissociavelmente ligado ao índio, é praticamente impossível pensar em Castro Alves sem a causa abolicionista ${ }^{1}$. Daí o popular epíteto de "poeta dos escravos".

Passemos então ao drama de Castro Alves. De clara inspiração romântica, Gonzaga ou a Revolução de Minas teve uma primeira encenação, ainda amadora, na Bahia, em fevereiro de 1868, e, posteriormente, uma bem sucedida estréia em São Paulo, em outubro do mesmo ano (PRADO, 1996).

Com a intenção de perquirir-lhe algumas de suas peculiaridades, essencialmente no que diz respeito às questões, aqui centrais, da história e da literatura histórica, sigamos com uma breve análise da peça. Já em uma primeira leitura, fica clara a presença de três linhas condutoras do enredo, ou seja, a princípio, percebem-se três histórias, mas que, ao cabo, vão se reduzindo a duas. Vejamos quais sejam.

Primeiramente, temos o fio do tramar da Inconfidência. Já PRADO (1996) descrevia esse fio como o mais frágil dos três. A conjuração mineira é delineada como

\footnotetext{
${ }^{1}$ A leitura de Candido, pelo próprio objetivo da sua obra, se faz, no entanto, de forma mais profunda e é capaz de perceber, em análise do conjunto da produção de Castro Alves, uma profundidade que escapa à primeira vista. Para Candido, a temática do escravo é reflexo de uma crença mais profunda do poeta que veria a desarmonia do mundo como fruto das contradições entre homem e sociedade, entre oprimido e opressor.
} 
um movimento romanesco e idealista, sem pontos de apoio com a realidade. Bastante diferente disso, pesquisadores, como GANCHO e TOLEDO (1991), por exemplo, descrevem diversos planos de implantação da desmantelada república mineira.

Os próprios conspiradores não mostram grande crença no triunfo do movimento no mundo real e concreto, mas isso não os desanima, deixando transparecer uma visão de mundo cristã, em que a vitória não pertenceria ao plano material. $\mathrm{O}$ movimento e seus integrantes seriam como Cristo, "aquele que ganha ao perder", "que triunfa ao sacrificar a vida pelo bem da humanidade". Isso pode ser comprovado no diálogo travado entre os inconfidentes Cláudio Manuel da Costa, Inácio José Alvarenga, Tomas Antonio Gonzaga e o também conjurado vigário Carlos Correia de Toledo, em que Cristo é chamado de revolucionário e o papel do movimento é comparado a uma profecia bíblica. Diz o padre: "Foi o mestre quem o disse: 'eu vim quebrar os ferros, a todos os cativos e eles serão quebrados". Cláudio completa: "Padre, Cristo era um belo revolucionário" (ALVES, 1972, p.7).

O segundo fio do enredo pode ser percebido nas personagens de Luis e Carlota, escravos, pai e filha, separados há muitos anos pelas crueldades e inconsiderações do sistema escravista e que, até o presente da narrativa, ainda cultivam o anseio do reencontro. Luis, escravo liberto por Gonzaga, mas que continua a acompanhá-lo, tornase revolucionário ao perceber que o movimento pode mudar a situação do negro. Carlota, intimidada pelo seu senhor, o pérfido Joaquim Silvério dos Reis, (que sabe quem é o pai da moça e ameaça matá-lo, sem dizer a ela quem é), dispõe-se a espionar Maria (que a considera amiga). No meio da trama, ao sacar um rosário da mãe, descobre que Luis é seu pai. Segundo Décio de Almeida Prado, essa é uma das formas mais desgastadas de reconhecimento, de tal forma que já havia sido dado pelos franceses "o nome irônico de la croix de ma mère" (PRADO, 1996, p. 178). Carlota é, ao fím, sacrificada e Luis segue o ex-senhor na prisão e no exílio.

Há ainda o terceiro fio que seriam os amores de Gonzaga e Maria Dorotéia, e o triângulo formado com o Governador Visconde de Barbacena, que procurava impedir o casamento, retardando a licença de união que deveria vir da metrópole.

Assim, estabelecemos três linhas do enredo, mas podemos perceber, numa análise mais detida, que as duas primeiras caminham lado a lado. Na prótase, temos, além da apresentação das personagens e de seus respectivos objetivos, a conexão entre 
os inconfidentes e os escravos. Esse fato se dá desde o título do primeiro ato, "Escravos", que trata, não só dos escravos Luis e Carlota, mas também dos inconfidentes. É possível perceber o paralelo traçado entre Portugal/Brasil, no contexto da situação colonial e da exploração da mão de obra Branco/Negro.

A presença de duas linhas paralelas, a da Inconfidência e a dos escravos, se confirma na catástrofe, ou resolução do conflito. Dois enredos requerem dois encerramentos e é isso que temos nos atos terceiro e quarto. No ato três, "Os mártires", resolve-se o conflito da Inconfidência, enquanto no quatro, "Agonia e glória”, vemos a confirmação do amor de Gonzaga e da honra de Maria. A ligação entre as duas primeiras linhas é ainda mais clara, se atentarmos para alguns exemplos das falas de Luis e de Carlota ou de situações indicadas nas didascálias. Na reunião final, em que são traídos, cercados e levados presos pelo governador, cada um dos inconfidentes, antes de sair, diz a sua frase de incentivo. Tiradentes, por exemplo, clama: "É o rebate da glória, meus amigos (...) Ao pedestal da liberdade, brasileiros”. Cláudio ressoa: "Todos ao banquete da morte, revolucionários". Comparem-se essas falas com as do ex-escravo Luis:

"E nós também somos brasileiros, e nós também somos revolucionários, e nós também somos mártires (...) o sangue dos escravos dos homens é irmão do sangue dos escravos dos povos, ambos caem na face dos algozes, ambos clamam vingança ao braço do futuro" (ALVES, 1972, p. 121).

Fica bastante claro que os "escravos dos homens" são os negros, enquanto os "escravos dos povos" são os brasileiros do momento da ação, não mais os do momento da encenação, pois já havia se dado a Independência. Percebe-se também que um dos problemas foi resolvido, o da Independência, enquanto o outro, o da escravidão, persiste, pedindo ainda a ação do "braço do futuro".

Essa espécie de "chave interpretativa" se põe a mostra em outras oportunidades. Quando os conspirados vão presos, em fila, temos a seguinte indicação cênica: "Ouve-se ao longe o canto da escrava durante a cena que se segue: Eu sou a pobre cativa / A cativa de além-mar / Eu vago em terra estrangeira / Ninguém me quer escutar (...)” (ALVES, 1972, p. 129). Mais uma vez é clara a relação entre a situação nacional e a situação do escravo: ambos são cativos. Poder-se-ia inclusive explorar certa ambigüidade da expressão "além-mar", dado que a negra que canta é prisioneira "no" 
além-mar, ou seja, está em cárcere em terras separadas da sua pelo oceano. De forma aproximada, os brasileiros seriam cativos de governantes "do" além-mar, em outras palavras, de homens que vieram de terras ultramarinas e os fizeram prisioneiros.

A conexão entre as duas linhas de enredo se dá ainda nas palavras da personagem de Luis, ao ver morta a filha e encerrando o terceiro ato: "Que o teu sangue puro, caindo nas faces do futuro, lembre-lhe o nome dos primeiros mártires do Brasil" (ALVES, 1972, p. 131). É bem certo que as "faces do futuro", ainda vivendo sob um sistema escravocrata, estavam na platéia do drama, chocadas com o destino da pobre Carlota, brutalmente violada e morta pelos homens de Silvério dos Reis.

Como dissemos, o terceiro ato dá fim aos enredos dos escravos e da Inconfidência, enquanto o quarto, aos amores de Gonzaga e Maria. O herói está na prisão e, ainda assim, Luis o acompanha e fala a ele dos ardis do processo. Ocorrem outras manobras de Barbacena que não desistira de Maria. Após diversas artimanhas envolvendo cartas e pessoas ouvindo outras, às escondidas, confirma-se o amor de Gonzaga e a honra de Maria. Silvério se diz perseguido pelo povo e Barbacena não se satisfaz, crendo que os amantes são mais felizes na punição que ele na vingança. Um poema final mostra o destino dos inconfidentes.

Por fim, podemos perceber que os dois enredos já haviam sido revelados no próprio título e subtítulo da obra. Enquanto o primeiro, apenas com o nome próprio, nos remete ao herói, seus amores, seu destino e a sua grandiosidade, como os trágicos gregos, Édipo ou Tiestes, ou os shakespereanos, Hamlet ou Othelo. Já o segundo, o subtítulo, centra-se na revolução de Minas, o que, sabemos agora, envolve não só os brancos da elite, mas, na versão de Castro Alves, os negros e escravos.

Outro dado interessante que pode ser levantado diz respeito às personagens da peça, seus desejos e suas relações. Com tal intuito, procuraremos construir um modelo actancial, reduzindo-os, porém, aos aspectos acima. Ou seja, na visão de UBERSFELD, retomada tanto por RYNGAERT, (1996), quanto por PAVIS (2003), o modelo actancial seria composto por destinador, destinatário, sujeito, objeto, adjuvantes e oponentes. Para a demonstração a ser intentada aqui, bastariam sujeito, objeto, adjuvantes e oponentes. Vamos ao modelo, em relação a algumas personagens.

Gonzaga, assumindo o papel de sujeito, possui dois objetos (entendidos aqui, no sentido do modelo actancial, como aquilo que o move, aquilo que ele procura), 
desejando, tanto o amor de Maria Dorotéia, quanto a independência nacional. Como adjuvantes de ambos os projetos, temos os inconfidentes, incluindo-se mesmo o negro Luis. Como opositores, temos Joaquim Silvério dos Reis e o Visconde de Barbacena. O modelo actancial de Gonzaga é o que sintetiza as idéias centrais mais visíveis do enredo da peça.

Por outro lado, se realizarmos a mesma tarefa, pensando na personagem de Tiradentes, encontraremos com facilidade apenas o seu objeto que, como não poderia deixar de ser, é a liberdade da nação. Mas, ao procurarmos seus adjuvantes com cautela, não nos depararemos com eles tão rapidamente. Se pensarmos nos inconfidentes, como seria mais óbvio, veremos que não há uma completa harmonia entre eles e o mártir. Isso se torna bastante explicito na primeira cena do segundo ato, quando volta à cidade o governador, dificultando os planos de revolução aos olhos dos conjurados. Tiradentes, no entanto, não se intimida com a presença de Barbacena e diz aos outros inconfidentes, exceto Gonzaga:

"O governador? E que me importa o Governador? Esta espécie de homem crocodilo (...) Eu não sou mais que um pobre tenente do exército, mas afirmo-lhes que, a não ser a prudência infantil, ou grande politica dos senhores, como the chamam, eu já ter-lhe-ia surrado as costas com o pano da minha espada" (ALVES, 1972, p. 42).

Destarte, transparece nas palavras do Joaquim José da Silva Xavier, a insatisfação com os outros integrantes do movimento, principalmente no que diz respeito ao não entrar em ação, procurando negociar com homens que não merecem crédito, nem tão pouco respeito. Assim, se não são adjuvantes e atrasam, ou mesmo impedem, a realização dos desejos de Tiradentes são opositores, deixando a função de auxiliar desocupada.

Interessante reparar que o modelo actancial de Tiradentes é semelhante aos modelos de Luis e de Carlota. Luis deseja a revolução, mas, principalmente, encontrar a filha desaparecida. Quem ajuda Luis, se mesmo Gonzaga se diz incapaz de realizar-lhe a vontade? Não há adjuvantes também para o liberto.

Já Carlota deseja exclusivamente o reencontro com o pai. A repetição de um modelo semelhante ocorre com a jovem, que possui como opositor Joaquim Silvério dos 
Reis, a quem se somam todos os outros, não restando personagem algum para o papel de seu adjuvante.

A simpatia do autor pelos personagens escravos é tamanha que, para a percepção moderna de cor e raça, seu texto poderia passar por um tanto preconceituoso, ao caracterizá-los, embranquecendo-os. Carlota é "quase tão branca como qualquer um de nós" (ALVES, 1972, p. 82). E, no caso de Luis, a sabedoria é dada como uma característica do branco, da qual ele começa a partilhar: "a velhice tem o capricho de nos fazer um pouco brancos" (diz o liberto, apontando para o cabelo grisalho) (ALVES, 1972, p. 45).

Ao fim, pode-se dizer que os grandes mártires sacrificados pela Inconfidência Mineira, da maneira como foi recomposta por Castro Alves, se projetam em três personagens, Tiradentes, Luis e Carlota.

\section{Conclusão}

Vê-se, deste modo, que existe certa congruência entre a Inconfidência histórica e a reelaborada por Castro Alves. Como vimos, historiadores afirmam que o preconceito racial era pouco importante, da mesma forma que não havia um consenso entre os conjurados sobre a questão do fim da escravidão.

Já na peça, assoma-se à questão da independência, essa outra da abolição com igual fervor. Porém, ressalte-se que, quem trata a abolição como necessidade para a nação, é a estrutura da peça e não as personagens que representam os inconfidentes. Como se atestou, não há adjuvantes para os casos dos escravos, assim como não os há para Tiradentes. Nesse ponto, a peça nos remete ao momento histórico inconfidente por dois motivos. Primeiramente, é Tiradentes que acaba por ser o que encara a mais severa punição, enquanto os outros todos são poupados. A segunda questão é relacionada aos escravos, que tiveram da Inconfidência, como se disse, uma postura ambivalente, nunca sendo tratados como prioridade.

Portanto, no que diz respeito às questões relacionadas à literatura e à história, podemos dizer que a peça de Castro Alves tratou de unir dois assuntos de extrema importância para o Brasil do século XIX, a independência e a escravatura. Obviamente, um deles, àquela altura, já estava resolvido, enquanto o outro ainda precisaria de árduo trabalho, durante os mais de vinte anos que ainda o separavam da abolição. Desta forma, a reelaboração que a peça faz sobre a Inconfidência Mineira tem por propósito 
discutir apenas um problema contemporâneo da sociedade de Castro Alves, a existência da escravatura. Essa seria uma função que pode ser descrita como característica da literatura histórica: usar o passado para discutir o presente. Não haveria objetivo de inserir a questão escravista em uma história que, em nada, se relaciona com ela, se não para demonstrar o seu interesse para a sociedade do XIX, o que viria a se confirmar com o conhecimento do restante da obra do poeta de preocupação solidamente homogênea.

Isso nos faz concluir que a literatura pode até navegar em águas passadas, mas nunca deixará soçobrar o vínculo com o presente.

\section{REFERÊNCIAS}

ALVES, Castro. Gonzaga ou a Revolução de Minas. Rio de Janeiro, Serviço Nacional do Teatro, 1972.

PESAVIENTO, Sandra Jatahy. História \& literatura: uma velha-nova história. Revista Nuevo Mundo. 28/01/2006. Disponível em $<\underline{\text { http://nuevomundo.revues.org/index1560.html }>}$ Acesso em 12 mar. 2009.

FAUSTO, Boris. História Concisa do Brasil. São Paulo: Edusp/Imprensa Oficial, 2002.

BOSI, Alfredo. História Concisa da Literatura Brasileira. São Paulo: Cultrix, 2004. CANDIDO, Antonio. Formação da Literatura Brasileira. Belo Horizonte: Itatiaia, 1997, v. 2.

FARIA, João Roberto. Idéias teatrais. São Paulo: Perspectiva, 2001.

GANCHO, Cândida Vilares; TOLEDO, V.V. A Inconfidência Mineira. São Paulo: Ática, 1991.

OLIVEIRA, Almir. Gonzaga e a Inconfidência Mineira. São Paulo, Edusp, 1985.

PAVIS, Patrice. Dicionário do Teatro. São Paulo, Perspectiva, 2001.

PRADO, Décio de Almeida. História Concisa do Teatro Brasileiro. São Paulo: Edusp, 1999.

PRADO, Décio de Almeida. O Drama Romântico Brasileiro. São Paulo: Perspectiva, 1996.

RYNGAERT, Jean Paul. Introdução à análise do teatro. São Paulo: Martins Fontes, 1996. 